\title{
The Analysis of the Reasons for China's Rising Pork Prices in 2019
}

\author{
$\mathrm{Xu} \mathrm{Lili}^{1, *}$ \\ ${ }^{1}$ Administration management, Beijing Normal University, Beijing, China \\ *1769645561@qq.com
}

\begin{abstract}
Firstly, the paper introduces the abnormal rise of pork price in China in 2019. And then, it analyzes the reasons for rising pork prices from the demand side and the supply side. Through analyzing data and reviewing literature, it was found that the demand side was generally stable, and the problem was mainly due to the substantial reduction in the supply side. The specific reasons are as follows: the outbreak of the Infection with African swine fever virus(ASF), unreasonable promotion of local environmental protection policies and large-scale breeding policies, endogenous promotion of "hog cycle" and the imported pork can't make up the shortfall. This triggered our thinking in terms of market allocation of resources, policy formulation and implementation, and government regulation.
\end{abstract}

Keywords: Pork price; infection with African swine fever virus; policy formulation and implementation; the hog cycle

\section{INTRODUCTION}

China's rising pork prices came as a shock, so that some people joked that "now buying pork also needs installments". According to statistics published on the Ministry of Agriculture and Rural Affairs of the People's Republic of China, the overall price of pork in 2019 shows a trend of substantial increase, with only a slight decline at the end of the year. The average price of pork per month in 2019 was up to $47.09 \mathrm{CNY} / \mathrm{kg}$, which was 2.57 times the lowest price, as shown in Figure 1; and the annual average price in 2019 was much higher than in the previous years.

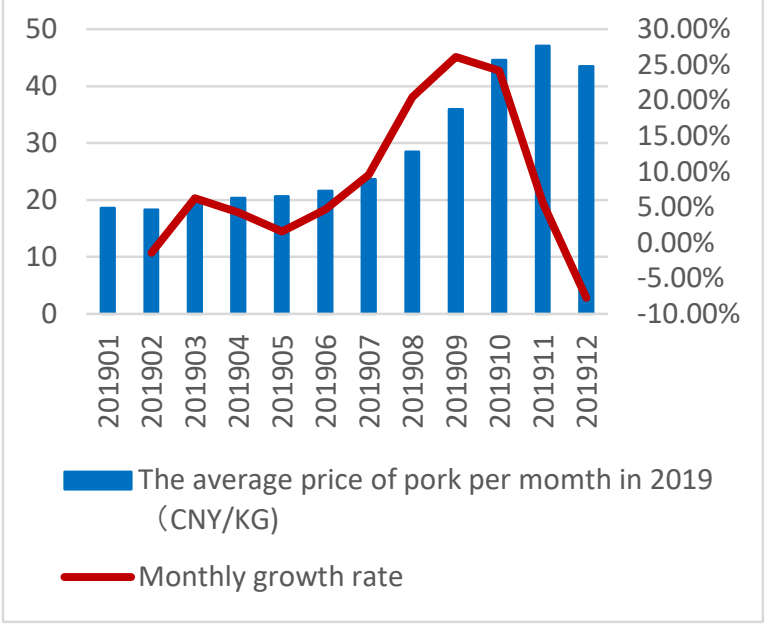

Figure 1 The average price and growth rate of pork per month in 2019

Source Ministry of Agriculture and Rural Affairs of the People's Republic of China

With the development of economy and the improvement of people's living standard, pork has become one of the daily necessities [1]. The rising price of pork has a direct impact on consumers' purchases and quality of life [2], and people are more likely to choose pork substitutes. In fact, as one of commodities, it is normal for pork prices to fluctuate slightly, which are manifested as fluctuations within and across natural years. In a natural year, pork prices are mainly influenced by holidays, such as the Mid-Autumn Festival and Spring Festival, when pork prices are significantly higher than in other months.Across natural years, pork prices are mainly influenced by the laws of supply and demand. When pork prices rise, farmers find it profitable to breed more pigs, leading to an oversupply of pork and a fall in prices. And then, farmers feel so unprofitable that they reduce the pig breeding, resulting in the supply of pork less than demand and the rise in price. Therefore, a unique term "hog cycle" was formed.

However, the pork prices fluctuated abnormally in 2019. Specifically, pork prices rose abnormally in a natural year and the average price was much higher than other years [3] The following will analyze the reasons for abnormal fluctuations in pork prices in 2019 .

\section{THE REASONS}

As one of the commodities in the market, the price fluctuation of pork is inevitably affected by the law of supply and demand. This paper analyzes the reasons for the abnormal fluctuation of pork price in 2019 from the perspective of demand and supply. Through the comparison of the supply and demand of pork market, it is found that the demand side of pork is relatively stable, and the problem mainly lies in the supply side. 


\subsection{The demand side of pork}

As the main meat consumption choice of Chinese residents [4], the total consumption of pork in China is in a relatively stable trend in recent years, and there is no abnormal increase in 2019. Pork consumption is mainly related to family income, consumer preferences, the price of substitutes, holidays and population. These factors did not change abnormally in 2019, which further indicates that the relatively stable demand side of China's pork market is not the reason for the abnormal fluctuation of pork price.

\subsection{The supply side of pork}

According to Figure 2, it can be seen that the overall pork production was stable from 2011 to 2018 in China, but pork production declined significantly in 2019, with a decline of up to $21.25 \%$. Under the condition of stable demand side, a large reduction in the supply side will inevitably lead to a substantial increase in pork prices. Next, we will analyze the reasons for the sharp decline in pork production in 2019.

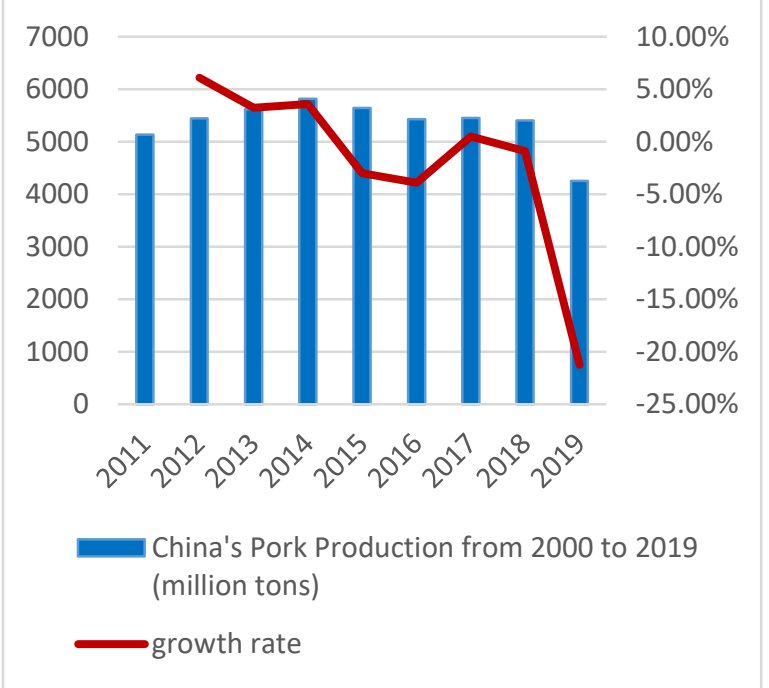

Figure 2 Changes in China's pork production from 2011 to 2019

Source National Bureau of Statistics

\subsubsection{The outbreak of Infection with African swine fever virus}

Infection with African swine fever virus (ASF) is an infectious disease caused by the African swine fever virus (ASFV) infecting domestic pigs and various wild boars. It is characterized by a short morbidity process and a high mortality rate [5]. The first confirmed case of ASF in China occurred on August 3, 2018 in Shenyang City [6]. Since then, ASF has spread in China. So far (January 1, 2020), it has been reported that nearly 1.2 million infected pigs have been culled, which has caused a relatively large impact on the supply of pigs [7].

At the beginning of the ASF, some places did not pay enough attention and supervision based on the ASF, which exacerbated the probability of pigs being infected, leading to the spread of ASF. In addition, some merchants carried out "south-to-north pig transfer" for the sake of profits, and sold the diseased pigs across provinces and regions after purchasing, which aggravated the transmission of the ASF among different places. According to relevant sources, due to the severe epidemic situation in Guangxi Province, several pig dealers in Henan Province used to go there to collect sick pigs and sell them in Henan. A pig in Guangxi costed 200-500 yuan, which is equivalent to one or two yuan per kilogram, while the price of pigs in Henan costed three or four yuan per kilogram. The huge profits drove several unscrupulous dealers to take risks, which is an important reason for the spread of ASF across the country.

\subsubsection{Excessive promotion of local environmental protection policies and large-scale breeding policies}

Another important reason for the decrease of pig supply in 2019 is the neglect of pig market rules in the implementation of some environmental protection policies [8] and large-scale breeding policies. The starting point of environmental protection policy and large-scale breeding policy is to prevent environmental pollution and improve production efficiency. However, in the policy process, some places had problems in the interpretation and implementation of policies [9]. In the implementation, on the one hand, some places misinterpreted policies; On the other hand, the masses lacked active and correct guidance, which caused unnecessary losses. Most of the current pork market in China is still dominated by family free-range breeding. Large-scale breeding policies have led to the withdrawal of a large number of retail households. However, due to the time required for pig breeding, qualified manufacturers had not kept up with the progress, which had caused the reduction in supply. In the process of developing large-scale breeding, the basic number of pigs should be guaranteed. 
Table 1 Some environmental protection policies and large-scale breeding policies

\begin{tabular}{|c|c|c|}
\hline Category & Year & The related content \\
\hline $\begin{array}{l}\text { Environmental } \\
\text { protection } \\
\text { policy }\end{array}$ & 2018 & $\begin{array}{l}\text { All commercial livestock and poultry } \\
\text { breeding activities in the first-grade } \\
\text { protection zones for drinking water } \\
\text { sources shall be banned and breeding } \\
\text { facilities shall be dismantled. } \\
\text { Large-scale livestock and poultry } \\
\text { farms discharging pollutants within } \\
\text { the Level-II protection zone shall be } \\
\text { dismantled or closed. }\end{array}$ \\
\hline \multirow{2}{*}{$\begin{array}{l}\text { Large-scale } \\
\text { farming policy }\end{array}$} & 2016 & $\begin{array}{l}\text { It is required that the proportion of } \\
\text { large-scale breeding of more than } \\
500 \text { heads should reach } 52 \% \text { by } \\
2020 \text {. }\end{array}$ \\
\hline & 2019 & $\begin{array}{l}\text { In } 2022 \text { and } 2025 \text {, major progress } \\
\text { will be made in upgrading the pig } \\
\text { industry and improving its quality. } \\
\text { The farming scale rate reached about } \\
58 \% \text { and above } 65 \% \text { respectively. }\end{array}$ \\
\hline
\end{tabular}

\subsubsection{Endogenous promotion of "hog cycle"}

"Hog cycle" refers to the phenomenon that the production and prices of pigs fluctuate cyclically. The law of market supply and demand determines the existence of the "hog cycle", and the growth cycle of pigs determines the time of the "hog cycle", which is about three to four years. The main factors affecting the "hog cycle" are the low standardized scale breeding, delayed information monitoring and pre-warning, epidemics and so on [10]. This not only affects the normal development of pig breeding industry, but also affects the quality of life of residents and the level of sociometric development.Driven by the market regulation, farmers adjust their pig breeding according to price guidelines, which takes a long time. When accidental factors appear in the pig market, it will affect the original "hog cycle".

Stimulated by the ASF [11], environmental protection policy [12] and large-scale breeding policy, the impact of this round of "hog cycle" is much greater than before. In addition to a long period of higher pork prices due to the reduction in pork supply, the time of "hog cycle"l also last beyond before. According to the growth cycle of pigs, it can be predicted that it is difficult for pork prices to return to their original state within a short period of time.

\subsubsection{Imported pork can't make up the shortfall}

Some people thought that importing pork could be one of the ways to ease the current rise of pork price [13], but they ignored the basic situations of China's pork imports and exports. The import of pig products in China was under 300,000 tons before 2006. And then, it kept growing from 2007 to 2016, including a record high of 3,112,100 tons in 2016. But the imports of pork dropped significantly in 2017 and 2018 [14]. Although China is a pork net importer, the proportion of pork imports in the country's total pork consumption is relatively small. In other words, China's pork market is highly dependent on the domestic market, and pork imports can not make up for the supply gap caused by factors such as the ASF.

The key to alleviating the dilemma of the abnormal rise in pork prices in 2019 lies in the domestic market. By analyzing the supply and demand of the domestic pork market, we will take targeted regulatory measures that are in line with market laws according to the reasons. First of all, it is necessary to increase the scale of hog breeding and improve the technology of hog breeding. Secondly, we must strengthen the safety and quality monitoring of pork, especially in the prevention of infectious diseases and the steroid clenbuterol in the breeding [15]. Finally, it's worth developing the further processing of pork products and improving their added value.

\section{SUMMARY AND REFLECTION}

The reasons for the higher price rises in 2019 are mainly due to abnormal changes in the supply side of the pork market, specifically the ASF, excessive promotion of local environmental protection policies and large-scale farming policies, endogenous promotion of the "hog cycle", and pork imports that are difficult to make up for supply. This reflects not only economic problems, but also new thinking in policy formulation and implementation, health and epidemic prevention. Based on the analysis of the above reasons, pork prices are expected to maintain a high price recently, which will directly affect the cost of living of individuals and the normal operation of the market.

China's abnormal rising pork prices in 2019 gives us the following enlightenment. Firstly, we should give full play to the decisive role of the market in resource allocation and make basic judgments based on the actual situation of the market. Secondly, Policy formulation should be based on actual research and investigation, and policy implementation must be fully supervised, especially preventing misinterpretation and over-implementation of policies. The last but not least, the government should play a supervisory role in market operations, for example, how to do a better job in health and epidemic prevention [16]. 


\section{REFERENCES}

[1] Yin,DH. Economic Research on Pork Price Fluctuation [J]. Economic Forum,2020(01):124-129.

[2] $\mathrm{Hu}, \mathrm{K}$. A brief analysis of the causes of pork price rise $[\mathrm{J}]$. Technology and Economic Guide,2020,28(10):240.

[3] Li, QY; Fu, FJ; Linghu, CP. Analysis on the main Causes of pork price Fluctuation in Guizhou Province in 2019[J]. Rural Economy and Science-Technology,2019,30(23):61-62.

[4] Li, RN. Analysis on the impact and Causes of current Pork Price rise [J]. Pigs Today,2020(03):47-48.

[5] Kang, HQ; Xiao, HF. Economic effect of rising pork price in China under the background of ASF [J].Research of Agricultural Modernization ,2020,41(03):493-501. DOI : 10.13872/j.1000-0275.2020.0040

[6] Hu, XD; Guo, SJ. Study on the Impact of Epidemic Situation on pig market Price -- Analysis on the Impact of African Swine Fever on industry and countermeasures[J].Price:Theory\&Practice,2018(12):51 -55.DOI: 10.19851/j.cnki.cn11-1010/f.2018.12.011

[7] Jin, JW. A Brief Analysis on the causes of pork price rise and how pig farms strengthen biosecurity management and prevention measures $[\mathrm{J}]$. BeiFang MuYe,2020(07):9.

[8] Zhong, MZ; Lin, C;Duan N. Impact of environmental protection policy changes on pig breeding industry.Swine Industry Science ,2015,32(8):90-91.

[9] Zhang, JH. Pig prohibition policy continues to increase, where should pig raising enterprises go? . Swine Industry Science,2016,33(11):142-143.

[10] Xiao, HL; Xie, RS; Xiao, QP. Influencing factors and countermeasures of pig cycle $[\mathrm{J}]$. China Animal Industry,2018(02):82-83.

[11] Xiao, HL; Tan, WB; Chen, YQ. Effects of African swine fever on pig cycle in China and countermeasures. Feed Review,2019(2):53-56.

[12] Full interpretation of the impact of environmental protection policies on the pig market. BeiFang MuYe,2018(3):12-13.

[13] Pork imports tend to increase prices of pigs moderated.Sichuan Animal \& Veterinary Sciences ,2019,46(12):10-11.

[14] Guo, HW. Analysis on the Current Situation and
Trend of Pork Consumption in China [J]. Today's Pig Industry,2018(04):60-67.

[15] Li, WX; Qiao, J; Yang, Y. Analysis on the impact of pork import on China's pig industry. Rural Economy and Science-Technology,2017,28(17):80-81.

[16] Zhao,CG; Li,H; Zheng, RQ. Research on the development strategy of pig industry under the situation of African swine fever. China Swine Industry,2020,15(1):21-24.

DOI: $10.16174 /$ j.cnki.115435.2020.01.004 